\title{
Effects and Remediation of unexpected events on the brand's reputation in the Network Environment
}

\author{
XIONG LU ${ }^{1, a^{*}}$ \\ ${ }^{1}$ Jiangxi College of Foreign Studies, Nanchang, Jiangxi, China \\ a646434632@qq.com
}

Keywords: Internet; emergencies; Brand reputation

\begin{abstract}
With the rapid development of network, social and economic life affected network everywhere. Especially the rise of Taobao in recent years, bring a rare opportunity for development to the traditional business. Facing the opportunities and challenges of the network, they either use network platform such as Taobao to fully expand marketing channels, or establish sales network platform by themselves to develop the electricity supplier business. However, the incident inevitably have an impact on electricity supplier in the process, Influence is how to produce and how to fix it? This is the content of what we want to explore in this article.
\end{abstract}

\section{Introduction}

Brand is a product or company in the minds of consumer loyalty and reputation, a direct impact on the purchase behavior of the product or service. For businesses, has a good brand has the important significance, it can be helpful to the enterprise to expand the product sales, to promote the enterprise development.

However, in the network environment, the establishment and development of the brand has its own characteristics. Compared with the traditional information dissemination channels, the Internet has the characteristics of timely and rapid communicate, eliminate the traditional time and space category. For business enterprises, the advantage is that the timely and rapid promotion of products, effective control channels, shorten the distance between the consumer, but the disadvantage is obvious. The Internet will allow some of the negative events to spread faster and wider. A small negative unexpected event, handled properly will rapid fermentation, causing serious impact on the enterprise.

\section{Evolution of emergencies impact on brand reputation}

The impact of emergencies on brand reputation, recent mainly in the Southern Airline emergency door event, network transmission speed and strength, and the impact on China Southern Airlines and emergency center, but also let us witnessed the power of Internet users.

The incident is November 9,2015, due to the need to go out, Mr. Zhang Liaoning reporters aboard China Southern Airlines flight to Beijing. During the flight, Mr. Zhang felt ill suddenly, and to the crew for help. After contact with the ground, the crew to help contact the ground emergency vehicles. However, perseverance more than one hour later, but the plane because a variety of reasons not open the cabin, delayed more than 50 minutes, then due to who help him get out of the plane, the crew and emergency center staff disputes between, and finally Mr. Zhang finally get out of the plane by himself, sitting on the car of emergency center.

Southern Airline and emergency center on negligence of staff of which, Mr. Zhang repeated complaints, none of onset. He had no choice but to write his own experiences in micro-blog, posted on his personal micro-blog. Micro-blog was released, immediately aroused the concern of Internet users nationwide, only the time of day, micro-blog reading amount to more than 9 million, and accounted for the major online media headlines. Subsequently, the Beijing News, CCTV and other traditional media have to intervene, it reported the incident, and to Southern and Beijing Emergency Center has a 
huge public pressure eventually caused a national health concern Planning Commission. Then, China Southern Airlines and Beijing Emergency Center has come to apologize.

From the evolution of the process point of view, several key nodes that Mr. Zhang's complaints are not well accepted, lead to dissatisfaction, followed by publication in the form of long micro-blog and then the users quickly follow, in turn the traditional media reports and events to climax. The power of micro-blog, Mr. Zhang's event is rippled in the network. Micro-blog in the dissemination of this event also played a crucial role. It also fully reflects the characteristics of the network environment emergencies, outbreaks quickly, fermented rapidly, affecting a wide face, serious injury.

\section{Factors affecting brand reputation diffusion in the network environment}

We can see From the China Southern Airlines emergency event that under the environment of network diffusion contingencies can be described as "lightning speed" and development Trend is difficult to predict, control is very difficult. The impact of the brand is also obvious. Once affected, a short time is difficult to repair. The author analyzes the impact of the network environment on the brand reputation of the impact of the main factors are the following:

Table 1. Influencing factors of the diffusion of brand reputation in the network environment

\begin{tabular}{|c|c|c|}
\hline Main factors & Important degree & Sequence of influence \\
\hline The degree of association with the vital interests & I & 2 \\
\hline Content authenticity and the level of communication & II & 4 \\
\hline Focus on opinion leaders and important platforms & III & 1 \\
\hline Enterprise response and response effect & IV & 2 \\
\hline
\end{tabular}

\subsection{The degree of association with the vital interests}

From the emergency door events, we can see that the staff of the emergency center and China Southern Airplane are also unmoved when the passenger life are threatened. Let people feel to them reflected the deep cold. Put yourself in their roles, also can let a person produce a kind of helplessness and frustration: if you encounter that environment, what is the situation? Furthermore, a lot of people will encounter such situation by airplane, if they have encountered such a situation, will they have an accidents? A plane ride so people will naturally worry, let alone ride a China Southern flight passengers.

\subsection{Content authenticity and the level of communication}

The emergency door incident, Mr. Zhang himself as a reporter, to his personal experience record the whole process under the events, plus writing skills flow, the event from start to finish intensively been described, basically in fact speak, text readability and its ability to persuade are strong, causing users attention. These have provided the most basic conditions for the spread of events.

\subsection{Focus on opinion leaders and important platforms}

In the incident, Mr. Zhang's micro-blog that is certified as "Liaoning Television News reporter," the micro-blog account. The micro-blog fans have 40185, which including some big V and celebrity micro-blog, by the end of the Phoenix news reprint forwarding number rapid growth and caused the attention of major network media successful. And after "Today's headlines" concerns, this event is attracting the attention of Internet users nationwide, a time this micro blog all over the network.

\subsection{Enterprise response and response effect}

In the complaint process, enterprise for Mr. Zhang's complaint did not care, repeated complaints were for various reasons to shirk, resulting in Mr. Zhang helpless, had to resort to the network, and eventually led to the incident, and to China Southern Airlines and the city of Beijing Emergency Center caused irreparable damage. If the enterprise can discover and response rapidly, the matter is likely to be resolved soon and will not have such a significant impact. It is also due to the low level of corporate response, so that the event has repeatedly fermented, and ultimately caused the concern of the national ministries, become a national public opinion events. 


\section{Reputation restoration under Network Environment}

In the network environment, to maintain a positive image of good business, we must first understand the development process of the entire network of public opinion. See from the fermentation process of the network public opinion, often to experience several steps such as latent, fermentation, outbreak, a secondary outbreak, They presented spiral upward trend. The map of network attention changes over time is shown below.

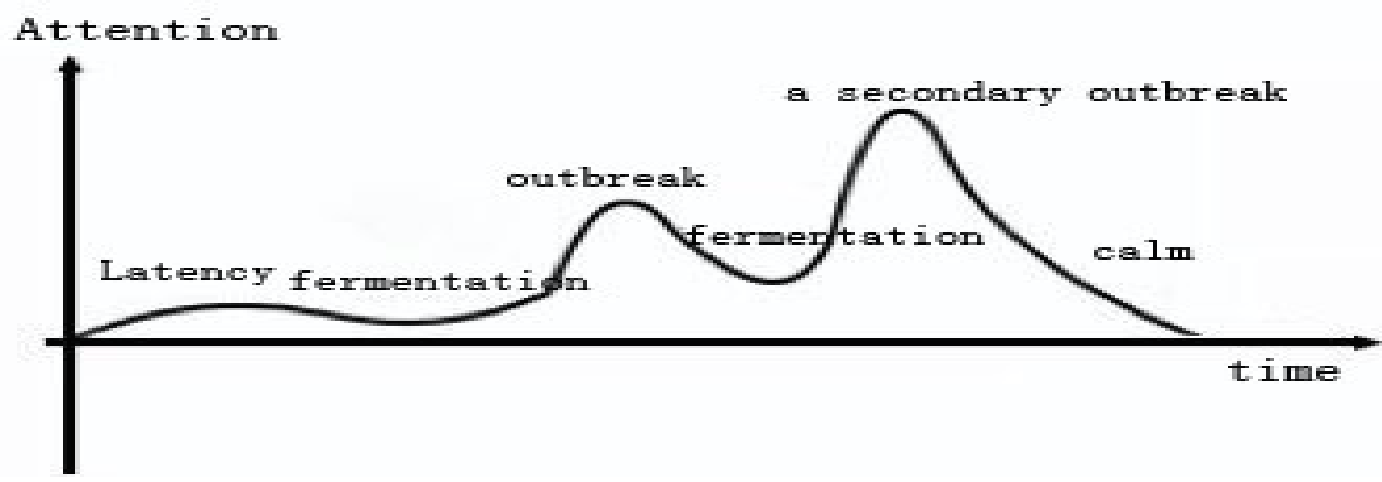

Figure1. The map of network attention changes over time

In the era of traditional media, the event once in the past, it basically becomes past, it is difficult to become the focus of attention again. However, the network is different, once negative events occur on the network there will leave traces of the corresponding. If users want to understand the relevant companies or products, through the way of network search is easy to search out the negative events again. For businesses, the potential impact of negative events will be greater than the traditional media.

We can see from the figure that the latent stage and the 2 stages of fermentation play a vital role in the development of negative public opinion. Therefore, enterprises in the maintenance and repair of the image process, with particular attention to this several key nodes. Generally speaking, is to find the first time, the first time to deal with, the first time to resolve. Because under the network environment, corporate reputation is often more vulnerable, especially large enterprises, prone to negative events of the network onlookers, timely repair corporate reputation, mainly from the following several aspects:

\subsection{With a sincere attitude touched each other}

In the network crisis event, the wisdom of the Internet users is infinite, only in good faith to impress each other. Once there is any false, it may cause a strong rebound in Internet users, so in the repair mechanism must be the greatest sincerity, the most effective way to deal with. Image maintenance and restoration of the network environment, the most taboo is false. Obnoxious and dissatisfaction that is caused by the false display of affection is also a key factor causing loss. If in the incident of Southern Airplane emergency door event, Beijing Emergency Center can handle it at the first time, recognize their mistakes and compensate to Mr. Zhang after receiving the complaint of Mr. Zhang, the event may not cause so much impact.

\subsection{Firmly establish a sense of crisis public relations}

Into the Internet era, any hesitation may cause irreparable damage to the enterprise. Therefore, the responsible person must firmly establish a sense of crisis public relations, the network reputation as an important part of their own brand image maintenance, once a problem, you can conduct a crisis public relations, as far as possible to shorten the reaction time, the event before the event will be processed in the event. Firmly establish the awareness of crisis public relations. It is to be incorporated into the whole process of corporate image building. In the initial stage of the image, pay attention to the negative public opinion business surveillance and response, as well as in the development of the mid-late, we must always pay attention to public opinion surveillance and response network. Of course, firmly establish the network crisis public relations awareness, you need to use the network to consider the problem, such as speed over everything, for the first discovery, the 
shortest time to be resolved. The only way to win the initiative in the network environment is speed that can leave enough space for their future development. Secondly, the network consciousness also contains a customer first consciousness, extreme attention to the user experience, try every means to use new media and customers to maintain zero distance, close the distance with customers, and tap the potential demand and consumer behavior characteristics, and let users participate in product design, business model planning, users become the core of enterprise operations management.

\subsection{Strengthen communication and coordination of Internet Media}

To deal with the sudden negative hot events, social organizations, including the individual may be based on their own needs to establish a variety of virtual network public opinion environment, and to obtain the corresponding the position of opinion guide, to the Internet information played a role in the transmission and gatekeeper. Under the condition that the network source is more than the people's ability to accept information, only the related events that people pay attention to will develop to online public opinion hotspot. Negative information content can only rely on a large amount of views and influence of various large web sites, to enlarge the influence of the agenda which people focus on, the formation of public opinion crisis; at the same time, it will be the search site placed in front of the search results, driven by more Internet users to participate in the agenda. Therefore, strengthen communication and coordination of Internet media, especially the spread of influential websites coordination by strengthening the supply and dissemination of checks, is very important.

\subsection{Choose reasonable information release and channel}

Information publisher's identity is related to the authenticity and validity of the source, and the choice of the information distribution channel directly determines whether the information can be transmitted to each other effectively. Thus, in response to the repair process, for information release and channel choice need to be cautious. How to publish and how to publish is a big problem. Publish and good responds can be a very good transfer of the topic, leading to the event gradually subsided. If the response is Inappropriate, then it is likely to re emergence of a new crisis. The timing of the release of information is very important for the negative public opinion of the network. After the negative event gradually subsided, it should continue to focus on the incident. Because of the search and divergence of the network, related negative public opinion events up public opinion is likely to erupt again after a certain event occurs.

\section{Conclusions}

In general, the network environment for enterprises to deal with emergency response and reputation of the repair, should uphold the principle of timely and prompt, once the event of fermentation, have an important impact, but also to take reasonable and effective measures, after the event also should be the greatest sincerity to save, with other events to shift the attention of Internet users, as far as possible to minimize the impact.

\section{References}

[1] Mudambi S M,Schuff D. What Makes a Helpful Online Review? A Study of Customer Reviews on Amazon. com [J]. Manage Informa- tion Science Quarterly. 2010,34( 1) : 185 -200.

[2] Huang P,Lurie N H,Mitra S. Searching for Experience on the Web: An Empirical Examination of Consumer Behavior for Search and Experience Goods [J]. Journal of Marketing,2009,73 : 55 -69.

[3] Bhaskar B. \& Bowonder B, Innovation as an enhancer of brand personality: globalization experience of titan industries [J]. Creativity and Innovation Management, 2001, 10(1):26-39.

[4] Selnes F,Gonhaug K. Effects of Supplier Reliability and Benevo- lence in Business Marketing [J]. Journal of Business Research, 2000,49( 3) : 259 - 271.

[5] Zheng Wenzhe, Wang Shuinen, the concept, characteristics and cultivation of enterprise reputation, maintenance - Journal of Jinhua Polytechnic[J] , 2004. 
